\title{
Analysis of Volatile Components of Auricularia auricula from Different Origins by GC-MS Combined with Electronic Nose
}

\author{
Lijun Fu, ${ }^{1}$ Gen Yang, ${ }^{2}$ Li Liu, ${ }^{1}$ Yongzheng Ma, ${ }^{1}$ Xiumin Zhang, ${ }^{1}$ Xin Zhang, \\ Changqin $\mathrm{Li}^{2,3}$ and Yong Sun $\mathbb{1 D}^{1}$ \\ ${ }^{1}$ Beijing Academy of Food Sciences, Beijing 100050, China \\ ${ }^{2}$ National $R$ \& D Center for Edible Fungus Processing Technology, Henan University, Kaifeng 475004, China \\ ${ }^{3}$ Functional Food Engineering Technology Research Center, Kaifeng 475004, Henan Province, China \\ Correspondence should be addressed to Yong Sun; sy183509@163.com
}

Received 25 May 2020; Revised 16 September 2020; Accepted 23 October 2020; Published 7 November 2020

Academic Editor: Fuguo Liu

Copyright (c) 2020 Lijun Fu et al. This is an open access article distributed under the Creative Commons Attribution License, which permits unrestricted use, distribution, and reproduction in any medium, provided the original work is properly cited.

Auricularia auricula is a kind of nutrient-rich edible fungus, which has the reputation of "king of vegetarians." In this paper, the electronic nose combined with GC-MS technology was used to analyze the volatile components of A. auricula in Heilongjiang, Jilin, Shanghai, and Sichuan provinces to investigate the differences and characteristics of $A$. auricula in different origins. The results showed that the electronic nose could obviously distinguish the samples from Jilin and Shanghai with a high degree of discrimination, while it was inappropriate to distinguish the samples from Heilongjiang and Sichuan Province. GC-MS was used to further analyze the volatile compounds in A. auricula qualitatively and quantitatively. The results showed that 98 volatile components were detected and 23 of them were common components, including alcohols, aldehydes, acids, esters, hydrocarbons, and other volatile components. The relative content of acetic acid and diethyl azodicarboxylate in A. auricula from the four origins was relatively high. According to the relative odor activity value (ROAV), it was found that the key compounds that caused the aroma difference between different origins were 1-octene-3-ol, cis-3-nonene-1-ol, (E)-2-octenal, $(E)$-2-nonenal, (E,E)-2,4nonadienal, and 3-methyl butanal.

\section{Introduction}

Auricularia auricula, a kind of gum fungus with edible and medicinal value [1], belongs to family Auriculariaceae [2]. It has been used as food and medicine for thousands of years. A. auricula's function of promoting blood circulation and invigorating the lung was recorded in Shennong Herbal Classic which is the earliest book about Traditional Chinese Medicine. A. auricula has many active compositions including cellulose, polysaccharides, melanin, calcium, iron, and phosphorus. For example, A. auricula polysaccharide has the function of improving human immunity as well as the effects of antitumor, antioxidant, hypoglycemic, and hemostatic [3-6]. However, so far, the sensory indices, such as color or shape, instead of these critical components are used to evaluate the quality of $A$. auricula for consumers. It is necessary and important to establish a fast and accurate analysis method.

As a new odor scanner developed in recent years, electronic nose had been widely used in medicine, food, beverage, cosmetics, and other fields. Welearegay et al. [7] used electronic nose to diagnose the helminth infectious diseases based on the patience's exhalations. Li et al. [8] used this technology to distinguish the Kiwifruit from different origins in China. Niu et al. [9] combined electronic nose, odor threshold, gas chromatography, and olfactory measurement methods for analysis of apple juice ester compounds. Mei et al. [10] used this technology to study the quality of perfume. The electronic nose uses a series of builtin gas sensors to get different response signal maps for different odors to identify these odors, which can detect and analyze the characteristics of volatile components in the 
tested samples conveniently and accurately [11]. But it has limitations in relation to its inability to perform qualitative and quantitative analysis on some special volatile components.

GC-MS can analyze the types and contents of volatile components in the measured samples but cannot study the contribution of these volatile components to the overall odor as a whole [12-14]. The analysis results of GC-MS can complement the results of electronic nose, so the combination of the two technologies can analyze the sample odor from the macro and micro level. At present, electronic nose combined with GC-MS technology has become an effective method for fast and accurate analysis of the overall odor as well as the detailed volatile components and their contents. Furthermore, the contribution of the characteristic compounds can be determined by calculating relative odor activity value (ROAV) [15]. To date, the literature mainly focuses on the medicinal efficacy of $A$. auricula polysaccharides and melanin [16, 17], but rarely on its volatile components and sensory quality, except a few researches such as that conducted by Li et al. [18] about the comparative study on the basswood and bagging A. auricula.

In this paper, electronic nose and GC-MS are combined to detect and analyze volatile components of A. auricula from four different origins from the macro and micro perspectives, and the types, contents, and ROAV of different volatile components from the different origins are compared.

\section{Materials and Methods}

2.1. Materials. Forty-four batches of A. auricula were collected from Heilongjiang, Jilin, Sichuan, and Shanghai Province in China. The sequence of batches in relation to locations is as follows: Hei 1-Hei 15, Ji 16-Ji 30, Chuan 31Chuan 36, and $\mathrm{Hu} 37-\mathrm{Hu} 44$, respectively.

2.2. Instruments and Equipment. Electronic nose (SuperNose-14) was purchased from ISENSO corporation (NYC, USA) and gas chromatography-mass spectrometry (GCMSQP2010UL) was from Shimadzu corporation (Kyoto, Japan).

2.3. Detection Method of Electronic Nose. The sample was grinded into powder and placed in $80^{\circ} \mathrm{C}$ water with a headspace bottle. Then, $10 \mathrm{~mL}$ gas was collected from the headspace bottle and injected into the sample pipeline through inlet system. The data acquisition time was $2 \mathrm{~min}$. In order to ensure the reliability of the results, each sample was tested three times.

2.4. Detection Method of GC-MS. GC-MS was equipped with DB-5 MS capillary column $(0.25 \mu \mathrm{m} \times 30.0 \mathrm{~m} \times 250 \mu \mathrm{m})$. The ion source temperature of the mass spectrometer was set at $230^{\circ} \mathrm{C}$ and the injection temperature was $250^{\circ} \mathrm{C}$. The temperature program for the column was set as follows: the column temperature was increased from $110^{\circ} \mathrm{C}$ to $180^{\circ} \mathrm{C}$ at the rate of $5^{\circ} \mathrm{C} / \mathrm{min}$ and held for $4 \mathrm{~min}$, then increased to $210^{\circ} \mathrm{C}$ at the rate of $3^{\circ} \mathrm{C} / \mathrm{min}$ and held for $8 \mathrm{~min}$ at $210^{\circ} \mathrm{C}$, and finally increased to $230^{\circ} \mathrm{C}$ at the rate of $5^{\circ} \mathrm{C} / \mathrm{min}$ and held for 3 minutes.

2.5. Data Processing. The Unscrambler statistical software was used to analyze the data collected from electronic nose with principal component analysis (PCA) and Loadings analysis. Qualitative and quantitative analysis of volatile substances were also determined; the molecules of each peak were identified by the given molecules with similarity greater than $85 \%$ according to the NIST library. The peak area normalization method was used for quantitative analysis to obtain the relative content of each volatile substance. ROAV calculated according to the following equation was adopted to determine the key aroma compounds:

$$
\begin{aligned}
\mathrm{ROAV}_{i} & =\frac{\mathrm{OAV}_{i}}{\mathrm{OAV}_{\text {max }}} \times 100, \\
\mathrm{OAV} & =\frac{C_{i}}{\mathrm{OT}_{i}},
\end{aligned}
$$

where $\mathrm{OAV}_{i}$ is the odor activity value of any one of the origin samples; $O A V_{\max }$ is the component with the highest OAV value of the origin samples; $C_{i}$ is the relative content of a compound; and $\mathrm{OT}_{i}$ is the aroma threshold of the compound in water.

\section{Results}

3.1. Analysis of A. auricula from Different Origins on Electronic Nose Assay. PCA is conducted to refine and transform the crude information of samples obtained from the electronic nose sensor into useful information, so as to obtain the most important factor with the largest contribution rate, and show the differences among samples from the PCA distribution map $[19,20]$. The overall aromas of $A$. auricula from different origins were compared and analyzed by PCA of the electronic nose sensor response value.

In Figure 1, the total contribution rate of the first two principal components (PC-1 and PC-2) was $94 \%$ indicating that the two components retain most of the information of the samples and could adequately show the similarity among the samples. As the laws of the two-dimensional PCA algorithm, it is known that the greater the distance between samples in the PC-1 horizontal axis direction, the greater the difference between samples. For the contribution rate of PC-2 (5\%) to the overall aroma was much smaller than that of the PC-1 $(89 \%)$, even if the distance of the samples in the PC-2 vertical axis direction was large, the actual difference between the samples would not be obvious [21]. According to this theory, it can be seen from Figure 1 that samples from Jilin had obvious differences compared with samples from the other three origins from the PC- 1 aspect. Besides, the differences between the samples from Jilin and Shanghai were mainly distributed in the positive area and negative area, respectively, which were obvious in the PC-2 aspect. The results indicated that PC-1 and PC-2 could be used to distinguish the samples collected from Jilin from others efficiently. For the A. auricula 


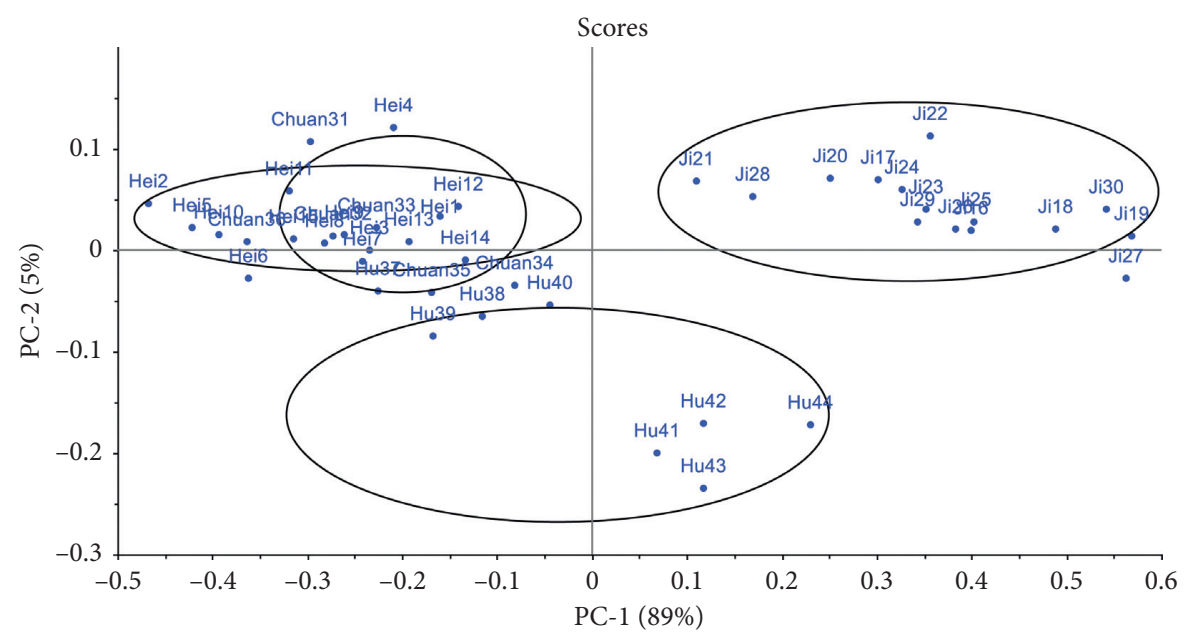

Figure 1: Principal component analysis of Auricularia auricular from different origins.

samples were, samples $\mathrm{Hu} 41-\mathrm{Hu} 44$ from Shanghai gathered together (Figure 1) and kept at a certain distance with the other samples, while samples $\mathrm{Hu} 37-\mathrm{Hu} 40$ were close to the samples from Heilongjiang and Sichuan. On the other hand, the samples of Heilongjiang and Sichuan almost completely overlapped, indicating that the electronic nose technology could not distinguish the $A$. auricula from Heilongjiang and Sichuan, but it could distinguish these samples from that of Jilin and some of Shanghai. According to references, PCA method could be successfully applied to the identification of the origin of Chinese medicinal materials such as Moutan cortex, Angelica sinensis, and Pleurotus eryngii [22-24].

Compared to PCA algorithm method focusing on the samples, Loadings algorithm is on each sensor of the electronic nose. The latter can be used to evaluate the ability of different sensors to distinguish the sample [25], and the position in the Loadings analysis chart can reflect the contribution rate of every sensor to the volatile odor of the sample. The farther away from the origin of coordinates $(0,0)$, the greater contribution of this sensor to the sample odor. In contrast, the closer to the origin of coordinates, the smaller contribution of this sensor to the sample odor [26]. The Loadings analysis result of $A$. auricula in Figure 2 demonstrates that the S1, S2, S4, S5, S6, S7, S9, S10, and S11 sensors had a relatively large contribution to the samples.

Super nose has 14 built-in sensors, and different sensors have their own response strength to different volatile components. The sensor array and its performance specification are shown in Table 1.

In Table 1, the S1, S2, S4, S5, S6, S7, S9, S10, and S11 sensors have strong response signals to aromatic compounds, nitrogen oxides, low molecular amines, organic acid ester, terpenes, esters, sterols, triterpenes, oxygenated derivatives, hydrogen, furan compounds, and VOC. It can be concluded that these substances largely contribute to the overall aroma of $A$. auricula

3.2. Analysis Results of GC-MS. Results of volatile components of $A$. auricula from four different origins by GC-MS are shown in Table 2 . There are a total of 98 volatile components and 23 common components detected from the samples. The analysis results of volatile components of Auricularia auricular from different origins are shown in Table 3.

Alcohols, aldehydes, acids, esters, and alkanes account for the majority of the detected compounds. The relative content of alcohols, aldehydes, acids, and esters was relatively high.

\section{Comparative Analysis of Various Volatile Compounds}

4.1. Alcohols. Alcohols are the basic materials for the synthesis of perfumes in the perfume industry. Most alcohols can produce pleasant fragrance, such as flowers and fruits [27]. A total of 21 alcohols were detected from the samples of A. auricula where the number of the alcohols in the samples from Heilongjiang, Jilin, Shanghai, and Sichuan was 15, 15, 9, and 13, respectively. Among them, isoamyl alcohol, 1hexanol, 1-butanol, 1-octene-3-ol, 1-nonanol, and 1-amyl alcohol were the common components from the four origins. Meanwhile, 1,4-pentanediol, trans-2-decen-1-ol, 1heptanol, and cis-3-nonene-1-ol were the unique volatile components in Jilin, which might be the reason for the obvious aroma difference between the samples collected from Jilin and the others by the super nose.

4.2. Aldehydes. Aldehydes generally have a lower aroma threshold than alcohols, so even if the content of aldehydes is low, they often have a great contribution to the overall aroma [28]. The largest number of volatile compounds detected in A. auricula was aldehydes, with a total of 30 types, and there were 20,24, 9, and 9 types of aldehydes in Heilongjiang, Jilin, Shanghai, and Sichuan, respectively. Among them, 1hexanal, (E)-2-heptanal, and 2-undecylenal were the common compounds in samples from all origins, while $(E, E)$ 2,4-dodecadienal, $(E)$-2-octenal, $(E, E)$-2,4-heptadiena, $(E)$ 2-nonenal, $(Z)$-2-heptenal, tridecanal, $(E, E)$-2,4-honadienal, (E)-2-undecenal, and trans-4,5-epoxy-2(E)-decenal were the unique components in $A$. auricula from Jilin Province. 


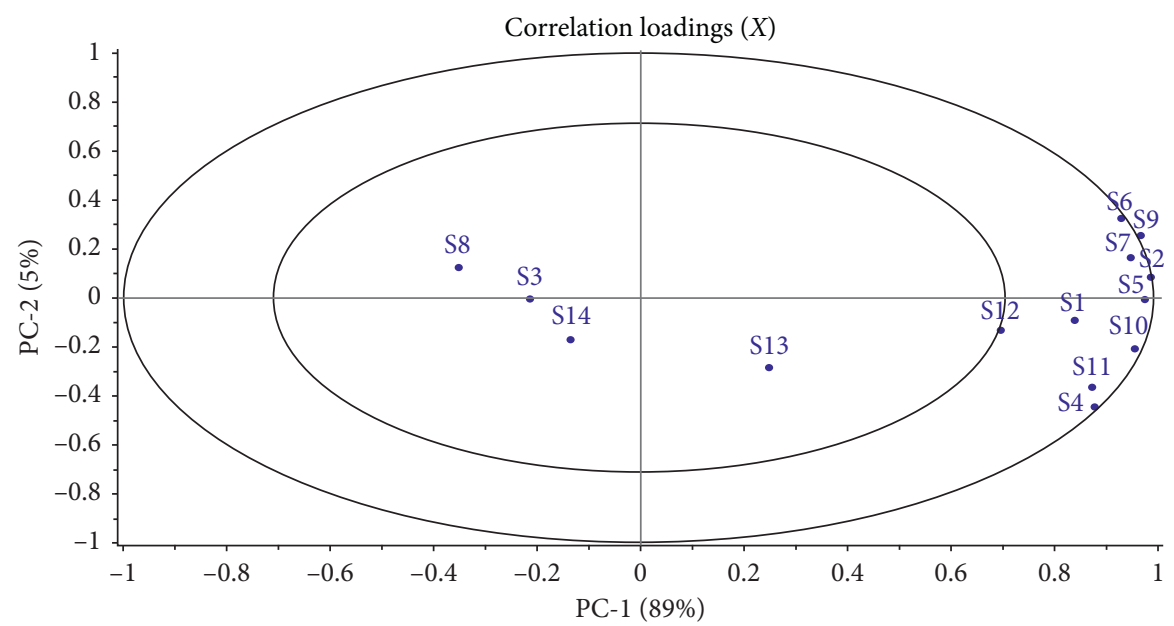

FIGURE 2: Loadings analysis of Auricularia auricula from different origins. (S1-S14 are 14 sensors of super nose).

TABLE 1: Standard sensor arrays and performance specification in electronic nose.

\begin{tabular}{lc}
\hline Sensors & Classification \\
\hline S1 & Aromatic compounds \\
S2 & Nitrous oxide, low molecular amines \\
S3 & Sulfide \\
S4 & Organic acid ester, terpene \\
S5 & Terpene, ester \\
S6 & Sterols, triterpenes \\
S7 & Oxygenated derivatives \\
S8 & Amine \\
S9 & Hydrogen \\
S10 & Furan compounds \\
S11 & VOC \\
S12 & Sulfide \\
S13 & Ethylene \\
S14 & Lactones, pyrazines \\
\hline
\end{tabular}

4.3. Acids. There were 8 types of acid compounds in A. auricula from the four origins. Among them, acetic acid, isovaleric acid, and caproic acid were the common components. In addition, acetic acid was the most prevalent ranging within $40.31 \% \sim 50.88 \%$. Isobutyric acid $(0.13 \%)$, 2,4-dihydroxybenzoic acid (0.13\%), and 6-ethyl-3dichloroacetic acid $(0.10 \%)$ were the unique volatile components of the samples from Heilongiiang. It is speculated that their contribution to the sample fragrance is limited because of their low relative content. Nonanoic acid was only found in samples from Jilin, but it would contribute less to the overall aroma of the sample because of its higher aroma threshold. The result was consistent with the results of $\mathrm{Li}$ Xiang in the analysis of the volatile components of Basswood and Bagging A. auricula [18].

4.4. Esters and Hydrocarbons. A total of 11 kinds of esters and 19 kinds of hydrocarbons were detected from the samples. Diethyl azodicarboxylate, isopentyl acetate, gamma-butyrolactone, hexyl acetate, and isobornyl acrylate were all the common ester components of A. auricula.
Among them, diethyl azodicarboxylate was the ester with the highest concentration $(50.29 \% \sim 79.16 \%)$, but it generally existed in all the samples, so it could not cause different aroma of A. auricula between different origins. Among the detected common hydrocarbons, the saturated hydrocarbons account for the majority, such as 4,6-dimethyldodecane and pentacosan. Meanwhile, only two unsaturated hydrocarbons, 1-undecyne and $D$-limonene, were detected.

Most of the hydrocarbons detected were saturated hydrocarbons with generally low relative content and high aroma threshold, so these components had little effect on the overall aroma of A. auricula. But there are also some unsaturated hydrocarbons exhibiting strong and unique aroma. For example, $D$-limonene can enrich the sample's aroma and give the sample a pleasant fresh lemon and orange flavor aroma [29].

4.5. Others. There were also some ethers, furans, and other components in A. auricula. 5-Methyl-2 (3H)-furanone, 2pentylfuran, N-butylphenylsulfonamide, and acetonitrile were all common compounds of $A$. auricula. Cholesterol (5.92\%) and 1-methoxy-2-propanol $(0.16 \%)$ were unique to the samples from Sichuan, while 2-methylpyrazine existed only in the samples from Heilongjiang and Jilin at $0.53 \%$ and $0.07 \%$, respectively.

4.6. Results of ROAV Analysis. In order to explore the role which volatile components in A. auricula played in the overall aroma and analyze the differences of them among different origins, this part adopted ROAV to determine the key volatile components. Generally, the larger the ROAV of one volatile compound, the greater the contribution of the compound to the overall aroma of the sample. The compound with $R O A V \geq 1$ means that it is the key aroma compound of the sample, and the compound with ROAV between 0.1 and 1 means this compound plays an important role in the overall aroma of the tested samples [30, 31]. According to the equation listed in Section 2.5, the ROAV of 
TABLE 2: Composition and relative content of volatile components in the four kinds of Auricularia auricula.

\begin{tabular}{|c|c|c|c|c|c|c|}
\hline \multirow{2}{*}{ Number } & \multirow{2}{*}{ Compound name } & \multirow{2}{*}{ Molecular formula } & \multicolumn{4}{|c|}{ Relative content $/ \%$} \\
\hline & & & Heilongjiang & Jilin & Shanghai & Sichuan \\
\hline \multicolumn{7}{|l|}{ Alcohols } \\
\hline 1 & Ethanol & $\mathrm{C}_{2} \mathrm{H}_{6} \mathrm{O}$ & 38.66 & 19.41 & - & - \\
\hline 2 & Isoamyl alcohol & $\mathrm{C}_{5} \mathrm{H}_{12} \mathrm{O}$ & 9.12 & 9.95 & 8.28 & 8.78 \\
\hline 3 & Isobutanol & $\mathrm{C}_{5} \mathrm{H}_{12} \mathrm{O}$ & 3.79 & - & - & 0.54 \\
\hline 4 & 1-Hexanol & $\mathrm{C}_{6} \mathrm{H}_{14} \mathrm{O}$ & 2.28 & 4.17 & 3.77 & 2.49 \\
\hline 5 & 1-Butanol & $\mathrm{C}_{4} \mathrm{H}_{10} \mathrm{O}$ & 1.37 & 2.86 & 2.19 & 1.53 \\
\hline 6 & 1-Octene-3-ol & $\mathrm{C}_{8} \mathrm{H}_{18} \mathrm{O}$ & 1.17 & 2.44 & 2.71 & 1.90 \\
\hline 7 & 4-Methyl-3-heptanol & $\mathrm{C}_{8} \mathrm{H}_{18} \mathrm{O}$ & 0.90 & 1.65 & - & 0.62 \\
\hline 8 & 1,3,5,7,9-Pentaethyl-1,9-Dibutyl alcohol & $\mathrm{C}_{4} \mathrm{H}_{10} \mathrm{O}$ & 0.32 & - & - & 0.34 \\
\hline 9 & 1-Nonanol & $\mathrm{C}_{9} \mathrm{H}_{20} \mathrm{O}$ & 0.26 & 0.95 & 0.48 & 0.15 \\
\hline 10 & 2,3-Dimethyl-1-Butanol & $\mathrm{C}_{6} \mathrm{H}_{14} \mathrm{O}$ & 0.25 & 0.55 & - & 0.09 \\
\hline 11 & 1-Octanol & $\mathrm{C}_{8} \mathrm{H}_{18} \mathrm{O}$ & 0.25 & - & 0.48 & 0.18 \\
\hline 12 & 1- Amyl alcohol & $\mathrm{C}_{5} \mathrm{H}_{12} \mathrm{O}$ & 2.27 & 3.92 & 3.03 & 4.36 \\
\hline 13 & 2-Methyl-1-propanol & $\mathrm{C}_{4} \mathrm{H}_{10} \mathrm{O}$ & - & 2.51 & 1.10 & 0.73 \\
\hline 14 & Linalool & $\mathrm{C}_{10} \mathrm{H}_{18} \mathrm{O}$ & - & - & 1.30 & 1.09 \\
\hline 15 & Cyclohexanol & $\mathrm{C}_{6} \mathrm{H}_{14} \mathrm{O}$ & 1.19 & - & - & - \\
\hline 16 & 5-Methyl-2-(1-methylethyl)- 1-hexanol & $\mathrm{C}_{7} \mathrm{H}_{16} \mathrm{O}$ & 0.25 & 0.22 & - & - \\
\hline 17 & 2-Methyl-1-pentanol & $\mathrm{C}_{6} \mathrm{H}_{14} \mathrm{O}$ & 0.13 & - & - & - \\
\hline 18 & 1,4-Pentanediol & $\mathrm{C}_{5} \mathrm{H}_{12} \mathrm{O}_{2}$ & - & 0.27 & - & - \\
\hline 19 & (E)-2-Decen-1-ol & $\mathrm{C}_{10} \mathrm{H}_{20} \mathrm{O}$ & - & 0.15 & - & - \\
\hline 20 & 1-Heptanol & $\mathrm{C}_{7} \mathrm{H}_{16} \mathrm{O}$ & - & 0.23 & - & - \\
\hline 21 & Cis-3-nonen-1-ol & $\mathrm{C}_{9} \mathrm{H}_{18} \mathrm{O}$ & - & 0.32 & - & - \\
\hline \multicolumn{7}{|l|}{ Aldehyde } \\
\hline 22 & 3-Methyl butanal & $\mathrm{C}_{5} \mathrm{H}_{10} \mathrm{O}$ & 17.25 & 0.90 & - & - \\
\hline 23 & 2,4-Dimethylbenzaldehyde & $\mathrm{C}_{9} \mathrm{H}_{10} \mathrm{O}$ & 0.79 & - & - & - \\
\hline 24 & Trans-2-dodecen-1-al & $\mathrm{C}_{12} \mathrm{H}_{22} \mathrm{O}$ & 0.63 & 1.04 & - & - \\
\hline 25 & (E, E)-2,4-Decadienal & $\mathrm{C}_{10} \mathrm{H}_{16} \mathrm{O}$ & 0.50 & - & - & - \\
\hline 26 & $(\mathrm{E}, \mathrm{Z})$-2,4-Decadienal & $\mathrm{C}_{10} \mathrm{H}_{16} \mathrm{O}$ & 0.12 & 2.40 & - & - \\
\hline 27 & 5-Methyl furfural & $\mathrm{C}_{6} \mathrm{H}_{6} \mathrm{O}_{2}$ & 0.07 & - & - & - \\
\hline 28 & (E, E)-2,4-Dodecadienal & $\mathrm{C}_{12} \mathrm{H}_{20} \mathrm{O}$ & - & 0.72 & - & - \\
\hline 29 & (E)-2-Octenal & $\mathrm{C}_{8} \mathrm{H}_{14} \mathrm{O}$ & - & 1.27 & - & - \\
\hline 30 & (E, E)-2,4-Heptadienal & $\mathrm{C}_{7} \mathrm{H}_{10} \mathrm{O}$ & - & 0.47 & - & - \\
\hline 31 & (E)-2-Nonenal & $\mathrm{C}_{9} \mathrm{H}_{16} \mathrm{O}$ & - & 1.96 & - & - \\
\hline 32 & (Z)-2-Heptenal & $\mathrm{C}_{7} \mathrm{H}_{12} \mathrm{O}$ & - & 0.77 & - & - \\
\hline 33 & Tridecanal & $\mathrm{C}_{13} \mathrm{H}_{26} \mathrm{O}$ & - & 0.32 & - & - \\
\hline 34 & (E, E)-2,4-Nonadienal & $\mathrm{C}_{9} \mathrm{H}_{14} \mathrm{O}$ & - & 0.16 & - & - \\
\hline 35 & (E)-2-Undecenal & $\mathrm{C}_{11} \mathrm{H}_{20} \mathrm{O}$ & - & 1.04 & - & - \\
\hline 36 & 2-Methylglutaraldehyde & $\mathrm{C}_{6} \mathrm{H}_{12} \mathrm{O}$ & - & - & 1.21 & - \\
\hline 37 & Hexanal & $\mathrm{C}_{6} \mathrm{H}_{12} \mathrm{O}$ & 1.47 & 3.85 & 2.52 & 0.93 \\
\hline 38 & 1-Nonanal & $\mathrm{C}_{9} \mathrm{H}_{18} \mathrm{O}$ & 1.31 & - & 1.17 & 1.64 \\
\hline 39 & Pentanal & $\mathrm{C}_{5} \mathrm{H}_{10} \mathrm{O}$ & 0.65 & 2.45 & 1.76 & - \\
\hline 40 & Heptanal & $\mathrm{C}_{7} \mathrm{H}_{14} \mathrm{O}$ & 0.63 & 5.78 & - & - \\
\hline 41 & (E)-2-Heptanal & $\mathrm{C}_{7} \mathrm{H}_{12} \mathrm{O}$ & 0.35 & 1.58 & 0.57 & 0.11 \\
\hline 42 & 2-Undecenal & $\mathrm{C}_{11} \mathrm{H}_{20} \mathrm{O}$ & 0.29 & 1.40 & 0.35 & 0.43 \\
\hline 43 & 1-Decanal & $\mathrm{C}_{10} \mathrm{H}_{20} \mathrm{O}$ & 0.25 & 0.25 & 0.07 & - \\
\hline 44 & 3-Furaldehyde & $\mathrm{C}_{5} \mathrm{H}_{4} \mathrm{O}_{2}$ & 0.20 & - & 0.15 & - \\
\hline 45 & 1-Octanal & $\mathrm{C}_{8} \mathrm{H}_{16} \mathrm{O}$ & 0.19 & 0.57 & - & 0.03 \\
\hline 46 & 2-Dodecenal & $\mathrm{C}_{12} \mathrm{H}_{22} \mathrm{O}$ & 0.19 & - & 0.21 & 0.36 \\
\hline 47 & Dodecyl aldehyde & $\mathrm{C}_{12} \mathrm{H}_{24} \mathrm{O}$ & 0.19 & 0.25 & - & 0.07 \\
\hline 48 & (E, E)-2,4-Dodecadienal & $\mathrm{C}_{12} \mathrm{H}_{20} \mathrm{O}$ & 0.19 & 0.81 & - & - \\
\hline 49 & 1-Undecanal & $\mathrm{C}_{11} \mathrm{H}_{22} \mathrm{O}$ & 0.13 & 0.39 & - & 0.06 \\
\hline 50 & 2-Decenal & $\mathrm{C}_{10} \mathrm{H}_{18} \mathrm{O}$ & 0.41 & 1.31 & - & - \\
\hline 51 & 2-Furaldehyde & $\mathrm{C}_{5} \mathrm{H}_{4} \mathrm{O}_{2}$ & - & 0.07 & - & 0.06 \\
\hline 52 & Trans-4,5-epoxy-2(E)-decenal & $\mathrm{C}_{10} \mathrm{H}_{16} \mathrm{O}_{2}$ & - & 1.62 & - & - \\
\hline \multicolumn{7}{|l|}{ Acids } \\
\hline 53 & Acetic acid & $\mathrm{CH}_{3} \mathrm{COOH}$ & 43.09 & 40.31 & 50.88 & 45.59 \\
\hline 54 & Isovaleric acid & $\mathrm{C}_{5} \mathrm{H}_{10} \mathrm{O}_{2}$ & 0.32 & 1.02 & 0.54 & 0.30 \\
\hline 55 & Caproic acid & $\mathrm{C}_{6} \mathrm{H}_{12} \mathrm{O}_{2}$ & 0.29 & 0.75 & 0.60 & 0.19 \\
\hline 56 & $\mathrm{~N}$-Valeric acid & $\mathrm{C}_{5} \mathrm{H}_{10} \mathrm{O}_{2}$ & 0.11 & 0.27 & - & 0.16 \\
\hline
\end{tabular}


TABle 2: Continued.

\begin{tabular}{|c|c|c|c|c|c|c|}
\hline \multirow{2}{*}{ Number } & \multirow{2}{*}{ Compound name } & \multirow{2}{*}{ Molecular formula } & \multicolumn{4}{|c|}{ Relative content/\% } \\
\hline & & & Heilongjiang & Jilin & Shanghai & Sichuan \\
\hline 57 & Isobutyric acid & $\mathrm{C}_{4} \mathrm{H}_{8} \mathrm{O}_{2}$ & 0.13 & - & - & - \\
\hline 58 & 2,4-Dihydroxybenzoic acid & $\mathrm{C}_{7} \mathrm{H}_{6} \mathrm{O}_{4}$ & 0.13 & - & - & - \\
\hline 59 & 6-Ethyl-3-dichloroacetic acid & $\mathrm{C}_{2} \mathrm{H}_{2} \mathrm{C}_{12} \mathrm{O}$ & 0.10 & - & - & - \\
\hline 60 & Nonanoic acid & $\mathrm{C}_{9} \mathrm{H}_{18} \mathrm{O}_{2}$ & - & 1.71 & - & - \\
\hline \multicolumn{7}{|l|}{ Esters } \\
\hline 61 & Diethyl azodicarboxylate & $\mathrm{C}_{6} \mathrm{H}_{10} \mathrm{~N}_{2} \mathrm{O}_{4}$ & 57.28 & 53.59 & 79.16 & 50.29 \\
\hline 62 & Isopentyl acetate & $\mathrm{C}_{7} \mathrm{H}_{14} \mathrm{O}_{2}$ & 1.38 & 1.54 & 1.80 & 2.49 \\
\hline 63 & Isobutyl acetate & $\mathrm{C}_{6} \mathrm{H}_{12} \mathrm{O}_{2}$ & 0.95 & 3.44 & - & - \\
\hline 64 & Amyl acetate & $\mathrm{C}_{7} \mathrm{H}_{14} \mathrm{O}_{2}$ & 0.92 & 1.12 & - & - \\
\hline 65 & Gamma-butyrolactone & $\mathrm{C}_{4} \mathrm{H}_{6} \mathrm{O}_{2}$ & 0.65 & 0.85 & 0.86 & 1.04 \\
\hline 66 & Hexyl acetate & $\mathrm{C}_{8} \mathrm{H}_{16} \mathrm{O}_{2}$ & 0.38 & 0.37 & 0.26 & 0.21 \\
\hline 67 & N-Butyl acetate & $\mathrm{C}_{6} \mathrm{H}_{12} \mathrm{O}_{2}$ & 0.20 & 0.29 & - & - \\
\hline 68 & Hexyl formate & $\mathrm{C}_{8} \mathrm{H}_{16} \mathrm{O}_{2}$ & - & 0.40 & 0.00 & - \\
\hline 69 & Lactic acid isoamyl ester & $\mathrm{C}_{8} \mathrm{H}_{16} \mathrm{O}_{3}$ & 0.40 & - & - & - \\
\hline 70 & 1-Methyl-butyl laurate & $\mathrm{C}_{16} \mathrm{H}_{32} \mathrm{O}_{2}$ & 0.15 & - & - & - \\
\hline 71 & Isobornyl acrylate & $\mathrm{C}_{13} \mathrm{H}_{20} \mathrm{O}_{2}$ & 0.32 & 0.74 & 0.34 & 0.69 \\
\hline \multicolumn{7}{|c|}{ Hydrocarbons } \\
\hline 72 & Trichloromethane & $\mathrm{CHCl}_{3}$ & 1.26 & 0.69 & - & - \\
\hline 73 & 4,6-Dimethyldodecane & $\mathrm{C}_{14} \mathrm{H}_{30}$ & 0.66 & 0.54 & 0.47 & 1.25 \\
\hline 74 & 2,6,11-tRimethyldodecane & $\mathrm{C}_{15} \mathrm{H}_{32}$ & 0.30 & 0.15 & - & - \\
\hline 75 & 3-Ethyl-3-methylheptane & $\mathrm{C}_{10} \mathrm{H}_{22}$ & 0.24 & 0.16 & 0.23 & - \\
\hline 76 & 4,5-Dimethylnonane & $\mathrm{C}_{10} \mathrm{H}_{22}$ & 0.22 & 0.29 & - & - \\
\hline 77 & Dodecane & $\mathrm{C}_{12} \mathrm{H}_{26}$ & - & 0.36 & - & - \\
\hline 78 & Pentacosan & $\mathrm{C}_{25} \mathrm{H}_{52}$ & 0.14 & 0.44 & 0.07 & 0.03 \\
\hline 79 & 2-Methyl-tetracosane & $\mathrm{C}_{25} \mathrm{H}_{52}$ & 0.08 & 0.38 & - & - \\
\hline 80 & 6-Ethyl-2-methyl-octane & $\mathrm{C}_{11} \mathrm{H}_{24}$ & 0.06 & - & - & - \\
\hline 81 & 2-Methyl-7-oxazolyl [2.2.1] heptane & $\mathrm{C}_{7} \mathrm{H}_{12} \mathrm{O}$ & - & 0.74 & - & - \\
\hline 82 & 1,2-Dimethylcyclopentane & $\mathrm{C}_{7} \mathrm{H}_{14}$ & - & 0.16 & - & - \\
\hline 83 & 1-Bromododecane & $\mathrm{C}_{12} \mathrm{H}_{25} \mathrm{Br}$ & - & 0.23 & - & - \\
\hline 84 & Octadecane & $\mathrm{C}_{18} \mathrm{H}_{38}$ & - & 0.14 & & \\
\hline 85 & 4-Methyl-5-propylnonane & $\mathrm{C}_{9} \mathrm{H}_{20}$ & - & - & 0.15 & - \\
\hline 86 & 2,6,10-Trimethyldodecane & $\mathrm{C}_{15} \mathrm{H}_{32}$ & - & - & - & 0.15 \\
\hline 87 & Methylbenzene & $\mathrm{C}_{7} \mathrm{H}_{8}$ & 2.11 & - & - & - \\
\hline 88 & 1-Undecyne & $\mathrm{C}_{11} \mathrm{H}_{20}$ & - & 0.27 & - & - \\
\hline 89 & O-Cymene & $\mathrm{C}_{10} \mathrm{H}_{14}$ & - & - & 0.62 & - \\
\hline 90 & D-Limonene & $\mathrm{C}_{10} \mathrm{H}_{16}$ & - & - & 5.28 & - \\
\hline \multicolumn{7}{|l|}{ Others } \\
\hline 91 & N-Butylbenzenesulfonamide & $\mathrm{C}_{10} \mathrm{H}_{15} \mathrm{NO}_{2} \mathrm{~S}$ & 0.55 & 0.93 & 0.92 & 0.81 \\
\hline 92 & 2-Methylpyrazine & $\mathrm{C}_{5} \mathrm{H}_{6} \mathrm{~N}_{2}$ & 0.53 & 0.07 & - & - \\
\hline 93 & Acetonitrile & $\mathrm{C}_{2} \mathrm{H}_{3} \mathrm{~N}$ & 0.40 & 7.69 & 1.69 & 0.03 \\
\hline 94 & Cholesterol & $\mathrm{C}_{27} \mathrm{H}_{46} \mathrm{O}$ & - & - & - & 5.92 \\
\hline 95 & Anethole & $\mathrm{C}_{10} \mathrm{H}_{12} \mathrm{O}$ & 0.45 & - & 0.78 & 0.46 \\
\hline 96 & 1-Methoxy-2-propanol & $\mathrm{C}_{4} \mathrm{H}_{10} \mathrm{O}_{2}$ & - & - & - & 0.16 \\
\hline 97 & 5-Methyl-2 (3H)-Furanone & $\mathrm{C}_{5} \mathrm{H}_{6} \mathrm{O}_{2}$ & 0.09 & 0.16 & 0.30 & 0.07 \\
\hline 98 & 2-Pentylfuran & $\mathrm{C}_{9} \mathrm{H}_{14} \mathrm{O}$ & 0.46 & 0.96 & 0.83 & 0.34 \\
\hline
\end{tabular}

Note. “-” means not detected.

TABle 3: Analysis of volatile components of Auricularia auricular from different origins.

\begin{tabular}{|c|c|c|c|c|c|c|c|}
\hline Group & Number & Alcohols & Aldehyde & Acids & Esters & Hydrocarbons & Other \\
\hline Heilongjiang & 67 & 15 & 20 & 7 & 10 & 9 & 6 \\
\hline Jilin & 71 & 15 & 24 & 5 & 9 & 13 & 5 \\
\hline Shanghai & 38 & 9 & 9 & 3 & 6 & 6 & 5 \\
\hline Sichuan & 41 & 13 & 9 & 4 & 5 & 3 & 7 \\
\hline
\end{tabular}


TABLE 4: ROAV value of each component detected in A. auricula.

\begin{tabular}{|c|c|c|c|c|c|c|}
\hline \multirow{2}{*}{ Number } & \multirow{2}{*}{ Compound name } & \multirow{2}{*}{ Aroma threshold $(\mu \mathrm{g} / \mathrm{kg})$} & \multicolumn{4}{|c|}{ ROAV } \\
\hline & & & Heilongjiang & Jilin & Shanghai & Sichuan \\
\hline 1 & Ethanol & 100000 & 0.00 & 0.00 & - & - \\
\hline 2 & Isoamyl alcohol & 120 & 0.18 & 0.34 & 2.55 & 3.85 \\
\hline 3 & 1-Hexanol & 250 & 0.02 & 0.07 & 0.56 & 0.52 \\
\hline 4 & 1-Butanol & 5000 & 0.00 & 0.00 & 0.02 & 0.02 \\
\hline 5 & 1-Octene-3-ol & 1 & 2.71 & 9.96 & 100.00 & 100.00 \\
\hline 6 & 1-Nonanol & 50 & 0.01 & 0.08 & 0.35 & 0.16 \\
\hline 7 & 1-Octanol & 120 & 0.00 & - & 0.15 & 0.08 \\
\hline 8 & 1- Amyl alcohol & 4000 & 0.00 & 0.00 & 0.03 & 0.06 \\
\hline 9 & 1-Heptanol & 330 & - & 0.00 & - & - \\
\hline 10 & cis-3-Nonen-1-ol & 1 & - & 1.31 & - & - \\
\hline 11 & 3-Methyl butanal & 0.4 & 100.00 & 9.18 & - & - \\
\hline 12 & $(E, E)-2,4$-Decadienal & 0.07 & 16.56 & - & - & - \\
\hline 13 & (E)-2-Octenal & 3 & - & 1.73 & - & - \\
\hline 14 & (E)-2-Nonenal & 0.08 & - & 100.00 & - & - \\
\hline 15 & $(E, E)-2,4$-Nonadienal & 0.09 & - & 7.26 & - & - \\
\hline 16 & Hexanal & 4.5 & 0.76 & 3.49 & 20.66 & 10.88 \\
\hline 17 & 1-Nonanal & 1 & 3.04 & - & 43.17 & 86.32 \\
\hline 18 & Pentanal & 20 & 0.08 & 0.50 & 3.25 & - \\
\hline 19 & Heptanal & 3 & 0.49 & 7.86 & - & - \\
\hline 20 & (E)-2-Heptanal & 13 & 0.06 & 0.50 & 1.62 & 0.45 \\
\hline 21 & 1-Decanal & 1 & 0.58 & 1.02 & 2.58 & - \\
\hline 22 & 1-Octanal & 0.7 & 0.63 & 3.32 & - & 2.26 \\
\hline 23 & $(E)$-2-decenal & 0.3 & 3.17 & 17.82 & - & - \\
\hline 24 & 2-Furaldehyde & 3000 & - & 0.00 & - & 0.00 \\
\hline 25 & Acetic acid & 22000 & 0.00 & 0.01 & 0.09 & 0.11 \\
\hline 26 & Nonanoic acid & 3000 & - & 0.00 & - & - \\
\hline 27 & N-Butyl acetate & 66 & 0.01 & 0.02 & - & - \\
\hline 28 & Dodecane & 2040 & - & 0.00 & - & - \\
\hline 29 & 2-Pentylfuran & 6 & 0.18 & 0.65 & 5.10 & 2.98 \\
\hline 30 & Undecanal & 5 & 0.06 & 0.32 & - & 0.63 \\
\hline
\end{tabular}

Note. "-" means not detected.

some important volatile compounds in A. auricula are shown in Table 4.

In Table 4,17 compounds with $\mathrm{ROAV} \geq 1$ were detected, including isoamyl alcohol, 1-octene-3-ol, cis-3-Nonene-1-ol, 3-methyl butanal, $(E, E)$-2,4-decadienal, $(E)$-2-octenal, $(E)$ 2-nonenal, $(E, E)-2,4$-nonadienal, hexanal, 1-nonanal, pentanal, heptanal, (E)-2-heptanal, 1-decanal, 1-octanal, (E)-2-decanal, and 2-pentylfuran which were the key compounds of $A$. auricula from corresponding origins. In addition, compounds $6,5,3$, and 5 with $0.1 \leq \mathrm{ROAV}<1$ in Table 4 were also important to the samples from Heilongjiang, Jilin, Shanghai, and Sichuan, respectively. These compounds mentioned above had an important contribution to the overall aroma of $A$. auricula; $(E)-2-$ Nonenal (1.96\%), cis-3-Nonene-1-ol (1.31\%), (E)-2-octenal $(1.27 \%)$, and $(E, E)-2,4$-nonadienal $(0.16 \%)$ were unique compounds in the samples from Jilin province, and their ROAV were $100,1.31,1.73$, and 7.26, respectively. Therefore, these four compounds were the key compounds of A. auricula in Jilin Province. Among them, (E)-2-nonenal had the highest contribution to the overall aroma. The results were consistent with that of electronic nose analysis.

3-Methyl butanal was the most prevalent ROAV compound in A. auricula from Heilongjiang, while it was the least prevalent in Jilin (9.18) and not detected in Shanghai, which revealed that it is one key odor compound distinguishing the sample from Heilongjiang from the others. At the same time, the relative content of $(E, E)$-2,4-decadienal was only $0.50 \%$, but its ROAV in Heilongjiang samples was much higher than 1 (16.96) for its low aroma threshold. In conclusion, both 3-methyl butanal and $(E, E)$ 2,4-decadienal were the characteristic aroma compounds of A. auricula from Heilongjiang.

Pentanal was detected in the Heilongjiang, Jilin, and Shanghai samples, but it was identified as a key compound only in Shanghai (3.25) according to the ROAV, whereas the ROAV was not high in the Heilongjiang and Jilin samples. Therefore, it might be beneficial in distinguishing the samples from Shanghai from those from other regions.

1-Octene-3-ol was detected in all the samples and belonged to key compounds according to the rule of ROAV in all of them as expected, because this compound was also known as mushroom alcohol with the aroma of fresh mushroom, licorice, and rose. Besides, it can also be used as pharmaceutical raw materials and spices [32]. 2-Pentylfuran has the aroma of fruit, bean, and similar vegetables [33] and it was also detected in the four origins. But it was the key 
compound in Shanghai and Sichuan and an important component in Heilongjiang and Jilin.

\section{Conclusion}

The PCA results of the electronic nose showed that the overall odor of $A$. auricula in Jilin area was significantly different from the other origins, and the samples in Jilin and Shanghai could be well distinguished from those from the other origins. However, the samples from Heilongjiang and Sichuan could not be distinguished well. Electronic nose could quickly distinguish the difference of the total odor of A. auricula among different provinces. GC-MS could detect the type and content of volatile compounds in the samples and thus it is helpful for further detailed identification. A total of 98 volatile components were detected, among which 23 components were common in the four provinces; the relative content of acetic acid and diethyl azodicarboxylate was relatively high. According to the relative odor activity value (ROAV), it was found that the key compounds that caused the aroma difference between different origins were 1-octene-3-ol, cis-3-nonene-1-ol, (E)-2-octenal, (E)-2nonenal, $(E, E)$-2,4-nonadienal, and 3-methyl butanal.

\section{Data Availability}

All original data used to support the findings of this study are included within the article.

\section{Conflicts of Interest}

All authors declare that there are no conflicts of interest regarding this study.

\section{Authors' Contributions}

Lijun Fu and Gen Yang contributed equally to this work.

\section{Acknowledgments}

This work was supported by the National Key R\&D Program of China, Project 2018YFD0400200.

\section{References}

[1] S. Sun, X. Zhang, W. Chen, L. Zhang, and H. Zhu, "Production of natural edible melanin by Auricularia auricula and its physicochemical properties," Food Chemistry, vol. 196, no. 1, pp. 486-492, 2016.

[2] T. Ye, L. Qian, and J. Cui, "Auricularia auricular polysaccharide protects myocardium against ischemia/reperfusion injury," Chinese Journal of Applied Physiology, vol. 26, no. 2, pp. 154-158, 2010.

[3] C. Sun, M. Jiang, and X. Duan, "Summarizing the value of medical and health care and development prospect on Auricularia auricular," Science and Technology Vision, vol. 12, pp. 17-18, 2013.

[4] D. Huang, Z. Liu, and Y. Zhang, "Review on anti-tumor mechanism of Auricularia auricular Polysaccharide," Journal of Plateau Agriculture, vol. 3, no. 6, pp. 694-699, 2019.

[5] H. Zhang, Z.-Y. Wang, Z. Zhang, and X. Wang, "Purified Auricularia auricular-judae polysaccharide (AAP I-a) prevents oxidative stress in an ageing mouse model," Carbohydrate Polymers, vol. 84, no. 1, pp. 638-648, 2011.

[6] G. Ma, W. Yang, L. Zhao, F. Pei, D. Fang, and Q. Hu, "A critical review on the health promoting effects of mushrooms nutraceuticals," Food Science and Human Wellness, vol. 7, no. 2, pp. 125-133, 2018.

[7] T. Welearegay, M. Diouani, and L. Österlund, "Diagnosis of human echinococcosis via exhaled breath analysis: a promise for rapid diagnosis of infectious diseases caused by helminths," The Journal of Infectious Diseases, vol. 219, no. 1, 2018.

[8] A. Li, S. Duan, and Y. Dang, "Origin identification of Chinese maca using electronic nose coupled with GC-MS," Scientific Reports, vol. 9, no. 1, 2019.

[9] Y. Niu, R. Wang, Z. Xiao, J. Zhu, X. Sun, and P. Wang, "Characterization of ester odorants of apple juice by gas chromatography-olfactometry, quantitative measurements, odour threshold, aroma intensity and electronic nose," Food Research International, vol. 120, pp. 92-101, 2019.

[10] X. Mei, Design of Electronic Nose System Used for Perfume Quality Evaluation, Jilin University, Changchun, China, 2015.

[11] A. Wilson and M. Baietto, "Applications and advances in electronic-nose technologies," Sensors, vol. 9, no. 7, pp. 5099-5148, 2009.

[12] A. J. Bergmann, G. L. Points, R. P. Scott, G. Wilson, and K. A. Anderson, "Development of quantitative screen for 1550 chemicals with GC-MS," Analytical and Bioanalytical Chemistry, vol. 410, no. 13, pp. 3101-3110, 2018.

[13] X. Xiang, Y. Wang, and Z. Yu, "Non-destructive characterization of egg odor and fertilization status by SPME/GC-MS coupled with electronic nose," Journal of the Science of Food and Agriculture, vol. 99, no. 7, pp. 3264-3275, 2018.

[14] Y. Fan, L. A. Yin, Y. Xue, Z. Li, H. Hou, and C. Xue, “Analyzing the flavor compounds in Chinese traditional fermented shrimp pastes by HS-SPME-GC/MS and electronic nose," Journal of Ocean University of China, vol. 16, no. 2, pp. 311-318, 2017.

[15] X. Pang, X. Guo, Z. Qin, Y. Yao, X. Hu, and J. Wu, "Identification of aroma-active compounds in Jiashi muskmelon juice by GC-O-MS and OAV calculation," Journal of Agricultural and Food Chemistry, vol. 60, no. 17, pp. 4179-4185, 2012.

[16] Y. Xu, M. Shen, Y. Chen et al., "Optimization of the polysaccharide hydrolysate from Auricularia auricula with antioxidant activity by response surface methodology," International Journal of Biological Macromolecules, vol. 113, pp. 543-549, 2018.

[17] R. Hou, X. Liu, J. Yan et al., "Characterization of natural melanin from Auricularia auricula and its hepatoprotective effect on acute alcohol liver injury in mice," Food \& Function, vol. 10, no. 2, pp. 1017-1027, 2019.

[18] X. Li, J. Deng, and H. Xu, "Comparative analysis of volatile components and key flavor compounds of basswood and bagging Auricularia auricula," Science and Technology of Food Industry, vol. 40, no. 5, pp. 249-252, 2019.

[19] M. Penza, G. Cassano, F. Tortorella, and G. Zaccaria, "Classification of food, beverages and perfumes by WO3 thinfilm sensors array and pattern recognition techniques," Sensors and Actuators B: Chemical, vol. 73, no. 1, pp. 76-87, 2001.

[20] D. Melucci, A. Bendini, F. Tesini et al., "Rapid direct analysis to discriminate geographic origin of extra virgin olive oils by flash gas chromatography electronic nose and chemometrics," Food Chemistry, vol. 204, pp. 263-273, 2016. 
[21] Y. Liu, L. Ge, and Y. Wang, "Analysis of volatile compounds and geographical origin discrimination of lu mountain clouds-mist tea by principal components analysis," Food Science, vol. 38, no. 24, pp. 60-67, 2017.

[22] C. Xia, Q. Song, and C. Fang, "Distinguish moutan cortex from different producing areas based on electronic nose technology," Chinese Journal of Modern Applied Pharmacy, vol. 36, no. 21, pp. 2633-2637, 2019.

[23] J. Gong, H. Zou, and J. Wang, "Rapid identification research on Angelica sinensis from different producing areas based on electronic nose technology," China Medical Herald, vol. 16, no. 28, pp. 39-43, 2019.

[24] Q. Ma, J. Bo, and L. Feng, "Effect of drying method on volatile components of Pleurotus eryngii analyzed by combined use of GC-MS and electronic nose," Food Science, vol. 40, no. 14, pp. 276-282, 2019.

[25] Q. Liu, N. Zhao, D. Zhou et al., "Discrimination and growth tracking of fungi contamination in peaches using electronic nose," Food Chemistry, vol. 262, pp. 226-234, 2018.

[26] S. Cao, C. Zhao, and F. Ma, "Aroma quality of different harvesting period Gastrodia elata by electronic nose and gas chromatography-mass spectrometry," Northern Horticulture, vol. 19, pp. 87-94, 2019.

[27] X. Su, "Alcohols compound: the basic material of aromatic chemicals," Value Engineering, vol. 29, no. 3, p. 39, 2010.

[28] D. Li, Y. Weng, and L. Du, "Detection of volatile compounds in different brands of Pu-erh tea using electronic nose and GC-MS," Food and Fermentation Industries, vol. 45, no. 3, pp. 237-245, 2019.

[29] H. Lu, Q. Zhong, and Z. Lin, "Study on the aroma components in Pu-erh tea with stale flavor," Journal of Tea Science, vol. 29, no. 3, pp. 219-224, 2009.

[30] Y. Zhang, S. Zhang, W. Fan, M. Duan, Y. Han, and H. Li, "Identification of volatile compounds and odour activity values in quinoa porridge by gas chromatography-mass spectrometry," Journal of the Science of Food and Agriculture, vol. 99, no. 8, pp. 3957-3966, 2019.

[31] D. Liu, G. Zhou, and X. Xu, "“ROAV” method: a new method for determining key odor compounds of rugao ham," Food Science, vol. 7, pp. 370-374, 2008.

[32] Q. Lu, F. Liu, and J. Bao, "Volatile components of American silver carp analyzed by electronic nose and MMSE-GC-MSO," Journal of Food Biochemistry, vol. 43, no. 3, 2019.

[33] C. Schueuermann, C. C. Steel, J. W. Blackman et al., "A GCMS untargeted metabolomics approach for the classification of chemical differences in grape juices based on fungal pathogen," Food Chemistry, vol. 270, pp. 375-384, 2019. 